\title{
Revisiting foundations in lot sizing - Connections between Harris, Crowther, Monahan, and Clark
}

\author{
Patrick Beullens \\ Mathematical Sciences and Southampton Business School and CORMSIS, \\ University of Southampton, SO17 1BJ Southampton, United Kingdom
}

\begin{abstract}
While many review articles exist on (deterministic) lot sizing models used in the context of price and quantity discounts, buyer-vendor coordination, supply chain management, and joint economic lot sizing problems, they do not convey the impact of important findings which date back to at least 2002, or, in hindsight, to 1984. As a result, many recent articles still model the financial implications of lot sizing decisions without having the assurance that these models would help the firm(s) involved in maximising the Net Present Value (NPV). This paper therefore reviews these findings, while adding also its own contributions, as to convey the general importance to lot sizing theory. We show that the underlying principles used in the four key articles that have led to a division in modelling approaches are in fact all in line with NPV, and argue that therefore there should not be these discrepancies that currently persist in the literature. We establish the connections between these four strands of literature using the solution to a simple variation of Harris' EOQ model, deriving thereby results from Boyaci and Gallego (2002) and Beullens and Janssens (2011), but showing their general applicability to any type of supply-chain structure. The breath of implications to deterministic lot sizing theory is illustrated using practical examples. We present a stochastic version of the model of Crowther (1964), which is arguably the least understood and applied model, but on the other hand the most important one in realising how these modelling strands can be unified.
\end{abstract}

Keywords: deterministic inventory, buyer-vendor coordination, joint economic lot sizing, quantity discounts, multi-echelon, pricing, net present value, stochastic regenerative demand 


\section{Introduction}

A theory of lot sizing is a set of models and algorithms to help find an optimal way of transferring batches of products through a supply chain in which these products undergo transformation, are held in stock, and are being moved on to the next stage(s). Such a theory would not be complete if it did not contain a set of founding principles that help explain in which context which models are applicable.

In particular, a firm may be interested in finding out how to model the impact that lot-sizing decisions will have on its future average profit. Since Harris (1913), it is well-known that lot sizing leads to financial holding costs that depend on the firm's opportunity cost of capital $\alpha$. Key contributions to the theory that allows a more refined investigation were made in Hadley (1964), Grubbström (1967), Grubbström (1980), Porteus (1985), Haneveld and Teunter (1998), Van der Laan and Teunter (2002) and Boyaci and Gallego (2002). At the time of writing, more than a decade later, this should have generated an important shift in modelling the financial implications of lot-sizing, in particular in the context of price/quantity discounts, joint economic lot-sizing, and supply chain coordination. However, there are still numerous contributions being published which are demonstrably not in line with these results (see Section 9). No review article has done justice to the implications that should have followed; any discussion on this topic is surprisingly absent in recent review articles. This discrepancy justifies the publication of a review-type paper with a focus on explaining the generality of these principles and demonstrating their practical implications.

Contributions. Given the above discrepancy found in the current literature, this paper's first aim is to bring a cohesive and accessible report of the key findings from the above articles, and the few more recent relevant articles, as to convey an appreciation of the general impact on modelling the financial implications of lot-sizing. To this aim, we naturally 'reproduce' some of the results previously obtained, but also offer some new contributions. The origins of the four key strands of lot-sizing modelling approaches can be traced back to Harris (1913), Clark (1958), Crowther (1964), and Monahan (1984). Differences between the models of Crowther and Monahan, and implications for coordination, are discussed in Boyaci and Gallego (2002), and links to Harris and Clark are identified in Beullens and Janssens (2011). What this paper adds to this discussion is a deeper understanding: by reviewing the

underlying reasoning of the authors of these classic papers, we see that there 
is in fact an important connection not previously recognised. We prove how this could have led to an alternative history in which the current discrepancies in modelling approaches would not have existed, but would have been replaced by one unified approach, from as early as 1984 .

In Harris (1913), when deriving the financial value of the average stock, Harris mentions that an irregular demand pattern would add additional complication, but concludes that it can generally be neglected or applied as a correction factor to the result. What Harris really meant with this comment is not known, but various plausible interpretations have been investigated (see Section 3). In this paper we will assign a different interpretation to Harris' comment about irregular demand patterns to arrive at a simple extension of his EOQ model. This model (in Section 3) is used to prove the connections between the four strands of lot sizing models investigated. Boyaci and Gallego (2002) were arguably first in deriving this result for the single supplier - multiple buyers setting, and Beullens and Janssens (2011) for the serial multi-echelon supply chain. Our contribution here, by viewing it as the result of an extension to Harris' model, is one of insight, namely, that the result represents the profit function of most firms more accurately in any supply-chain configuration. This is of pedagogical interest, since the generality of the key insight can be conveyed in a very natural manner in any introductory textbook on the topic of lot sizing.

As we will see, it is Crowther's model that is the key ingredient that is either missing or misinterpreted in the mainstream literature, while it nevertheless should appear naturally as part of the profit function of a firm. So far, (the relevance of) Crowther's model has only been shown to apply in deterministic models. In this paper, we generalise the profit function of the firm derived in Section 3 and derive a stochastic version of Crowther's model (Section 10). This proves its relevance beyond deterministic models, and the result also opens new avenues for further research.

To show the practical implications of this more unified theory to deterministic lot sizing theory, we present seven examples (Section 7) that complement those presented in earlier work. We illustrate why some classic inventory models will: (1) underestimate the value of price discounts and do not find the optimal scheme; (2) underestimate the value a firm is willing to invest in reducing its unit purchase price; (3) underestimate the value of joint lotsizing and do not find the joint optimal solution; (4) miscalculate side-payments that firms should exchange in order to arrive at a Nash Equilibrium; and, (5) how these errors will propagate in a multi-echelon supply 
chain. We further show: (6) the impact of payment structures, and (7) that the conditions under which the archetypal Joint Economic Lot Sizing (JELS) models can lead to equivalent results as those derived from NPV principles should necessarily deviate from the so-called 'conventional' payment assumptions (see further). In particular, we present two specific payment structures under which some JELS models from the literature do lead to results that are equivalent to NPV-derived JELS models. In general, we show that JELS research should pay explicit attention to the underlying payment structures if insights are to be derived concerning the relative benefits to the individual firms of adopting JELS solutions. This should be an important component of such research, but it is often missing.

Methodology. The main vehicle for our investigation is the use of Net Present Value (NPV) reference models. NPV modelling has been used at least for fifty years to check whether the lot sizing models we investigate are capable of maximising the NPV of the future profits of the firm(s) involved. The NPV value to the firm of its lot sizing activity is found as the Laplace transform of a cash-flow function (Grubbström, 1967) in which the Laplace frequency is taken to be the firm's opportunity cost of capital rate $\alpha$. As in Hadley (1964) and Grubbström (1980), we construct from this the Annuity Stream (AS) function. The AS is the constant stream of payments having the same NPV as a given stream of payments. In line with the models under investigation, we consider a continuous time and infinite horizon situation, and hence $\mathrm{AS} \equiv \alpha \mathrm{NPV}$. The linear approximation of exponential terms in $\alpha$ (containing decision variables) results in a profit function that can be compared with the functions in the classic lot sizing models.

The validity of a linearised model in approximating the AS is limited to situations in which cycle times are not much larger than one year, when $\alpha \approx 0.2$ (time measured in years). This is an acceptable limitation in many applications. Throughout its presentation, this paper assumes that payments for set-ups and production or procurement occur in full whenever a batch arrives at the firm, unless otherwise stated. This is called a conventional payment structure in Beullens and Janssens (2013). In Section 7.6 we extend this to a class of other payment structures, and show that by using a suitable substitution of parameters, the functional forms of the terms obtained under conventional payment structures are preserved.

Despite the technique of NPV-based modelling being quite well-known, it is somewhat surprising that the model of Crowther (1964) was not investigated in this manner until Boyaci and Gallego (2002), and that these findings 
do not seem to have made much of an impact as of yet (see Section 9). This article is therefore also a tribute to these authors, in the hope that future lot sizing theory will recognise the importance of their contributions. In Section 10, we transfer this key result to a stochastic setting by presenting, to our knowledge, the first NPV-derived stochastic version of the model of Crowther (1964).

The article's further organisation follows an order based on logic rather than chronology. We therefore introduce the extension of Harris' model using NPV-principles after the discussion of Harris (1913), and discuss Clark (1958) after Crowther (1964) and Monahan (1984). We postpone a discussion on relevant literature (Sections 8 and 9), after having established the key insights. Since models from various sources are discussed and compared, we introduce our own set of notation in an aim to be consistent throughout, but we pay careful attention to reproduce the original results accurately.

\section{Harris (1913)}

In the EOQ problem (Harris, 1913), a firm is to satisfy without shortages a constant demand rate $y$ per unit of time for an item, by procuring or producing at infinite rate in batches of equal size $Q=y T$ per unit of item, where $T$ is the cycle time. The cost for acquiring each unit of item is $c$, and the generation of each batch results in a fixed set-up cost $s$. The cost for interest and depreciation on stock is $\alpha$ per monetary unit and unit of time. All other parameters given constants, the optimal lot-size $Q$ that minimises the whole cost per unit of item and unit of time, and which is the sum of interest charges, set-up costs, and purchasing costs, as given by:

$$
\frac{\alpha}{2 y}(c Q+s)+\frac{s}{Q}+c
$$

is found to be $Q^{*}=\sqrt{2 s y / \alpha c}$. In addition to the derivation of this main result, Harris introduces the concepts of order lead-time and reorder point, and discusses their relationship; provides insight into the (in)sensitivity but asymmetry in the total costs around $Q^{*}$; and argues that the simplicity of the formula makes it easy to apply in practise.

Much of his reasoning remains convincing to date, and has been reconfirmed by extensive additional analysis. The EOQ model, for example, has been shown to be fairly accurately in line with the principle of maximising the Net Present Value (NPV) of the firm. For this purpose, one proposes a 
reference NPV model based on assumptions about an underlying cash-flow function for the firm. The simplest NPV model would take it that both $s$ and $c Q$ are paid out in full the moment a batch arrives, and that the first batch arrives at decision time 0 (i.e. the conventional payment structure, as introduced earlier). As in Hadley (1964), the Annuity Stream (AS) cost function for the firm is then given by:

$$
C(T)=(s+c Q) \sum_{i=0}^{\infty} \alpha e^{-i \alpha T}=\frac{\alpha(s+c Q)}{\left(1-e^{-\alpha T}\right)}
$$

where $\alpha$ is the continuous capital rate, representing the opportunity cost of capital for the firm. The Maclaurin expansion of the exponential term in $\alpha T$ produces $^{1}$ :

$$
C(T)=(s+c Q)\left(\frac{1}{T}+\frac{\alpha}{2}+\frac{\alpha^{2} T}{12}+O\left(\alpha^{3}\right)\right) .
$$

It can be verified that the linear approximation of (3) in $\alpha$, when divided by $y$, is indeed given by (1). When payment structures differ, this equivalence result is no longer guaranteed, see Beullens and Janssens (2013).

The expression (1), while being based on new notation, follows closely the original manuscript. Multiplication by the demand rate $y$, dropping the constant term on the interest charge on $s$, and substitution of the unit holding cost $h=\alpha c$ in (1), produces the better known relevant cost function per unit of time, as in Hillier and Lieberman (2005):

$$
h \frac{Q}{2}+s \frac{y}{Q}+c y
$$

and $Q^{*}=\sqrt{2 s y / h}$. The cost function (4) no longer shows the capital cost of $s$, and it would be more accurate to use Harris' original function (1) for decision problems in which $s$ would be variable. As this term typically remains insignificant when cycle times are less than a year, however, it is often acceptable to neglect it ${ }^{2}$. We will also adopt this simplification in the examples given in Section 7.

\footnotetext{
${ }^{1}$ Note that Disney and Warburton (2012) show how, by using the Lambert W function, one can obtain an optimal analytical solution to the unapproximated NPV profit function.

${ }^{2}$ See also Farvid and Rosling (2014), who develop a theoretically even more accurate method for dealing with set-up costs, of particular interest to stochastic models.
} 


\section{The EOQ for uniform stepsize cumulative demand}

Harris' comment about the potential impact of a deviation from the assumption of a constant demand rate (see Section 1) can receive various interpretations. It is now much better understood in which situations his EOQ result is robust, see e.g. Peterson and Silver (1985), how to deal with changing demand patterns through dynamic lot sizing theory (Wagner and Whitin, 1958), and which policies to use in stochastic systems, see e.g. Clark and Scarf (1960). In this paper we explore the consequences of adopting the assumption that demand in Harris' model is lumpy but deterministic and such that the cumulative demand over time follows a staircase of uniform stepsize. It can be regarded as a simple special case of a dynamic lot sizing problem, however, special attention is given to the impact of the (potentially variable) time length between two consecutive demand orders and the corresponding revenue stream it generates for the firm.

The problem is hence that a firm has to satisfy, without shortages, demand for a product that occurs with a constant average rate $y$ but for which the cumulative demand follows a staircase function of which each step is of a uniform height $Q$ and of a uniform length $T=Q / y$. The unit sales price $w$ is instantaneously received when the product is taken out of stock to fulfill demand, and a set-up cost $s_{p}$ is incurred to deliver the batch to the customer(s). The firm wishes to establish a stationary policy of ordering at infinite rate at a constant lot-size $Q_{s}$, incurring the set-up cost $s$ when the order arrives, and facing a unit cost $c$ when placing a product in inventory. Note that we assume, for now, that $Q$ (and $T$ ) is exogeneous. (For a graphical illustration of the problem, see Fig. 1 in Grubbström (2014) in which the demand curve is now a staircase of uniform steps.)

Theorem 1. The general form of the profit function for the firm facing the EOQ problem with uniform staircase cumulative demand, taken to be the linear approximation of its AS profit function, is given by:

$$
\Pi=(w-c) y-\frac{s y}{Q_{s}}-\frac{s_{p} y}{Q}-\alpha \frac{s+s_{p}}{2}-\alpha c \frac{Q_{s}}{2}+\alpha w \frac{Q}{2},
$$

and, more specifically for $Q_{s}=m Q$, as:

$$
\Pi=(w-c) y-\left(\frac{s}{m}+s_{p}\right) \frac{y}{Q}-\alpha \frac{s+s_{p}}{2}-\alpha(m c-w) \frac{Q}{2},
$$


where the optimal stationary policy is nested with lot-size $Q_{s}=m^{*} y T$, where:

$$
m^{*}=\left\lfloor\frac{1+\sqrt{1+8 \frac{s}{\alpha c y T^{2}}}}{2}\right\rfloor
$$

and the optimal time between two consecutive orders is $T_{s}^{*}=m^{*} T$.

Proof. The AS profit function of the firm, where $Q_{s}=y T_{s}$, is of the following form:

$$
\Pi\left(T_{s}\right)=\left(w y T-s_{p}\right) \sum_{i=0}^{\infty} \alpha e^{-i \alpha T}-\left(s+c y T_{s}\right) \sum_{i=0}^{\infty} \alpha e^{-i \alpha T_{s}} .
$$

The derivation of the optimal value for $T_{s}$ from (8) will produce an upper bound on profits, but will in general be infeasible since the cumulative quantities purchased by the firm at any one point in time must be sufficient to meet the cumulative demand without backorders. When viewing the system as a dynamic lot sizing problem with an infinite production rate, it is known that from both the NPV and the average cost perspective a so-called inner corner condition must be satisfied, see Grubbström and Molinder (1994) and Grubbström (2014). This means that the firm will only order at moments when a customer order is to be delivered, or in the terminology introduced in Roundy (1985), that the policy must be nested. Hence the optimal feasible lot-size $Q_{s}$ must be of the form $Q_{s}=m Q$, where $m \geq 1$ and integer. The linear approximation of (8) gives (5), and substitution of $Q_{s}=m Q$ gives (6), a profit function that is convex with respect to the integer variable $m$. In seeking the optimal value for $m$, say $m^{*}$, we follow the approach presented in Munson and Rosenblatt (2001) that the following conditions must be satisfied:

$$
\Pi\left(m^{*}+\delta\right) \leq \Pi\left(m^{*}\right), \text { for } \delta \in\{1,-1\} .
$$

Working out these conditions, and using the properties of quadratic equations, leads to (7), from which follows that $T_{s}^{*}=m^{*} T$. $\diamond$

Note that by rearranging terms, (6) can be rewritten as:

$$
\Pi=(w-c) y-\left(\frac{s}{m}+s_{p}\right) \frac{y}{Q}-\alpha \frac{s+s_{p}}{2}-\alpha c(m-1) \frac{Q}{2}+\alpha(w-c) \frac{Q}{2},
$$

and we recognise in this the supplier's profit function first proposed in Boyaci and Gallego (2002). 
Similarly to the conversion of Harris' original function (1) to (4), (6) could be simplified in order to provide only the relevant cost function per unit of time:

$$
C(m)=\frac{s}{m} \frac{y}{Q}+h m \frac{Q}{2},
$$

where $h=\alpha c$ can be interpreted as the (relevant) unit holding cost for the firm. This leads to the same optimal lot-size as given by $(7)^{3}$. The adoption of (11) may prove dangerous, however, when investigating situations in which $w, y$, or $T$ would be variable, as then a relevant part of the firm's opportunity costs and rewards in its profit function is no longer accounted for.

The holding costs for the firm as presented in (11) (and also in (5) and (6)) do not correspond to the conventional holding costs as found in the literature, where they would be calculated as being $h(m-1) Q / 2$ instead (i.e. the second to last term in (10)). This does not produce a different result insofar the derivation of $m^{*}$ for a given $Q$ is concerned ${ }^{4}$. However, the opportunity cost of a change in $c$, ceteris paribus, will be calculated differently. See also Section 7.2.

\section{Crowther (1964)}

About fifty years after Harris' seminal contribution, Crowther (1964) presents a model to provide a rationale for quantity discounts offered by a seller to its buyers. Every buyer is assumed to have an EOQ problem and derives Harris' EOQ formula from the average cost function:

$$
C_{b}(Q)=\frac{s_{b} y}{Q}+\alpha w \frac{Q}{2}
$$

where $w$ is the price per unit of product paid to the seller, $s_{b}$ a set-up cost for ordering, and $\alpha$ the interest rate. The novelty of Crowther's model is in presenting the impact on the seller's cost function when buyers order according to different values of $Q$. He argues that if it costs $s_{b}$ to a buyer to order, it will cost the seller $s_{b}$ to obtain this order. This is of course

\footnotetext{
${ }^{3}$ For example, we find (7) derived from a function (11) (in which $Q=1$ ) in GarcíaLaguna et al. (2010) for their EOQ model with integer lot size.

${ }^{4}$ The optimality of the integer lot-size ratio for the classic objective function was proven in Williams (1982).
} 
not necessarily $\mathrm{so}^{5}$. As in Harris' model, the average cost to the seller is $s_{b} y / Q$, and hence larger $Q$ will reduce it. Furthermore, and a crucial step, Crowther argues that if the buyer purchases in larger lots, the seller enjoys his profits earlier, which gives him a reinvestment potential in the business or elsewhere. At interest rate $\alpha$, and where $f$ is the per cent of profit on an item, he proposes that the seller's total gain can be correctly expressed as $\alpha f w Q / 2$, which also increases for larger $Q$. The seller's relevant cost function is hence:

$$
C(w \mid Q)=\frac{s_{b} y}{Q}-\alpha f w \frac{Q}{2} .
$$

For a given $w$, a larger $Q$ is hence always more profitable to the seller. Crowther demonstrates that if the seller can induce the buyers to order in lots sufficiently larger than their EOQ by offering a discount on a listed sales price $w$ that can at least cover the additional expenses of the buyer, the seller may enjoy a net reduction on (13). He discusses the concept of sharing profits through price setting, and offers a strategy for dealing with heterogeneous buyers and compliance to the Robinson-Patman Act.

Crowther provides numerical examples, and concludes that although the net savings from quantity discounts appear modest, he argues that firms typically sell numerous products to even more numerous buyers such that the total gain is by no means trivial. This paper is not focussing on the topic of price discounts, but suffice it to say that it is now well researched that price discounts are rational not only to reduce logistics costs but for various strategic and marketing reasons, see Dolan (1987) and Munson and Rosenblatt (1998), and in particular in the case of price-elastic demand, see e.g. Viswanathan and Wang (2003).

What is more important in the context of this paper is establishing to which extend Crowther's model is fundamental to lot sizing theory. We postpone more detailed comments on the literature to Section 9, but some important conclusions are well placed here. The literature review reveals that Crowther's article, if referenced, is acknowledged to be first in linking quantity discounts to lot sizing cost efficiency in the supply chain. His supplier cost function in its original conception is, however, rarely explained, even less reproduced, and almost never applied. To our knowledge, the first article to

\footnotetext{
${ }^{5}$ And to model this more general case, he could simply have introduced another parameter, say $s_{p}$, having the same interpretation as in Section 3 .
} 
revert back to Crowther's original model is Drezner and Wesolowsky (1989), who convert (13) into the following, more general, profit equation ${ }^{6}$ :

$$
P(w \mid Q)=(w-c) y+\alpha(w-c) \frac{Q}{2}-\frac{s_{p} y}{Q},
$$

where $c$ is the unit cost price for the seller and $s_{p}$ is the seller's specific set-up cost of acquiring (or delivering) the buyer's order. Very few articles since then have used Crowther's formulation (13) or (14).

Most articles that acknowledge the logistics benefit of larger lot sizes $Q$ for the seller use the formalism introduced in Dolan (1978) and Lal and Staelin (1984):

$$
P(w \mid Q)=(w-c) y+{ }^{\prime} h \frac{Q}{2}-\frac{s_{p} y}{Q},
$$

where ' $h$ ' is regarded as a constant, and the term in which it is used commonly described as the reduction in the supplier's holding costs. A seemingly convincing reason for assuming unit holding costs in general to be constant is that in numerical experiments, and since the price discounts are typically very small, the assumption produces good results, see e.g. Munson and Rosenblatt (2001) and Viswanathan and Wang (2003). It also simplifies the mathematical analysis. These are acceptable justifications in context. However, the general adoption of this simplification would not do Crowther's model justice since it will be shown to be of relevance also to other problems of supply chain coordination, such as in joint economic lot sizing problems, and it must hold for any (change in) value of $w$. It is in principle incorrect to interpret Crowther's term as being the negative of the seller's holding costs since the correct interpretation of ' $h$ ' is $\alpha(w-c)$, and hence it is not a unit holding cost reflecting the opportunity cost of capital invested in stock by the seller, but a unit supplier's reward reflecting the opportunity reward of

\footnotetext{
${ }^{6}$ Notice that Drezner and Wesolowsky (1989) have made changes to Crowher's model by using $s_{p} \neq s_{b}$ and $f w=(w-c)$. The latter is a more robust expression than $f w$ since this becomes inaccurate for large deviations to $w$ where one would expect $f$ to be a function of $w$ and not a constant. It is also more general in that the impact of changes to $y$ are now accurately described. Note that we have changed the sign of the seller's set-up cost term in comparison to Drezner and Wesolowsky (1989) to make it consistent with the common notion in lot sizing theory that it is a cost and not a reward. We also note that Crowther's article is, as in many other articles that cite him, wrongly referenced as published in the year 1967.
} 
receiving his profits in chunks (and hence earlier) rather than as a constant annuity stream at the rate of demand $y$.

It took about fifty years to confirm the equivalence of Harris' EOQ model to NPV under conventional payments. Note that Hadley saw this published in the same year, 1964, as Crowther saw his. It is somewhat surprising that yet another forty years have had to pass to investigate Crowther's model from the NPV viewpoint. To our knowledge, Boyaci and Gallego (2002) were first in confirming the NPV equivalence of Crowther's model, when adopting (14), under the assumption of conventional payments. They retrieve an interpretation ${ }^{7}$ of (14) as being accurate in describing the seller's total profit function in case that he would produce at infinite rate in lot sizes equal to $Q$. They investigate two other payment structures, the multiple buyers case, and discuss some of the implications for other models in the literature (see further). Despite this fundamental contribution, and while Boyaci and Gallego (2002) have received to date a good number of citations, they are not acknowledged for this result, and their lot sizing models in which Crowther's term is incorporated, have not been further used (see also Section 9).

Independently, Beullens and Janssens (2010) also retrieved Crowther's term in a linearised AS model of a seller-buyer model under conventional payments, and called it the supplier's reward. Results were later published in Beullens and Janssens (2011) were it was shown to play a role in every supplier's profit function in the serial multi-echelon supply chain, as well as in the EOQ with batch demand model of Grubbström (1980) and Kim et al. (1984). It was shown that assumptions about the placement of the so-called Anchor Point (AP) in the supply chain can affect the valuation of the sum of holding costs and supplier's reward to the firm.

It is clear from Theorem 1 that Crowther's result should be accounted for by any firm facing such 'lumpy' demand. Not accounting for this effect will underestimate the NPV of the activity for the firm. Also, the impact of changes to not only $Q$ and $w$ would be misrepresented, but also a change in its own production or procurement cost structure, as seen from the dependence on $c$. Crowther's contribution is, therefore, not restricted to the study of price

\footnotetext{
${ }^{7}$ Indeed, for $m=1,(10)$ becomes Crowther's function (when ignoring the constant term $\left.-\alpha s_{p} / 2\right)$ as given by (14) when adding the set-up cost $s$ to $s_{p}$. In addition, an alternative interpretation that proves the optimality of Crowther's model is to assume that $s=0$; then it is surely optimal to take $m=1$ and Crowther's model (14) applies.
} 
discounts of a firm with his buyer(s), but of much more general relevance.

\section{Monahan (1984)}

Exactly twenty years after Crowther's article was published, Monahan (1984) provides a concise account, in Section 2 of the article, for the rationale of quantity discounts from the seller's perspective. While not referring to Crowther (1964), it includes Crowther's main motivation. Monahan's formulation, in fact, is somewhat more accurate and to the point: 'This will mean a shift in both the magnitude and timing of order payments from the buyer. Hopefully, the vendor will then find he has use of more of the buyer's money, earlier in the year. This may be very important to the vendor, depending upon the size of his particular opportunity cost of capital.'

In developing his main model, Monahan, however, does not account for this effect. Moreover, he does not account for any inventory-related costs for the seller. This model can be stated as:

$$
C_{b}(Q)=w y+s_{b} \frac{y}{Q}+\alpha_{b} w \frac{Q}{2}
$$

for the buyer's cost function where $s_{b}$ is his set-up cost, $\alpha_{b}$ his opportunity cost rate, and $w$ the unit price paid to the supplier, and:

$$
P(w \mid Q)=f w y-s_{p} \frac{y}{Q},
$$

as the seller's profit function, where $f$ is, as in Crowther's model, the vendor's gross profit on sales, expressed as a percent ${ }^{8}$. He then introduces some extra parameters to model the discount scheme, and analytically derives the optimal scheme that the seller could use to set his price is such a way that the buyer's costs would not increase from adopting the discount scheme, while the seller would reap all remaining financial benefits. This is, in fact, an analytical solution to the approach that Crowther suggested. In modern terminology it would be classified as a Stackelberg game with the seller being the leader. Monahan extends his first model to account for transportation

\footnotetext{
${ }^{8}$ It is interesting to note that not only his reasoning, but also this peculiar modelling logic is the same. This may of course be due to them having consulted similar sources. Following the logic of Drezner and Wesolowsky (1989), we can replace the first term in (17) by $(w-c) y$.
} 
cost savings for the seller when offered a price discount scheme from the transporter. This is what Monahan is known for.

Interestingly, however, it is has never been further discussed in the literature that Monahan, in a final and short section, provides an extension that does address his earlier comment about the financial benefits to the seller, and which we have reproduced above. Adopting conventional payments, i.e. that the buyer pays the seller in full whenever an order is received, the AS profit function of the seller he arrives at can be represented $\mathrm{as}^{9}$ :

$$
\left(f w Q-s_{p}\right) \frac{\left(1-e^{-\alpha}\right)}{\left(1-e^{-\alpha Q / y}\right)}
$$

and he stops at this point. From his final comments it is clear that he thought that is would not produce an analytically tractable model.

If Monahan would have applied the linearisation technique of Hadley (1964), of which the general applicability to systems of production and inventory was demonstrated in Grubbström (1980), the linearised AS function he would have found:

$$
\Pi(w \mid Q)=f w y-\frac{s_{p} y}{Q}-\alpha \frac{s_{p}}{2}+\alpha f w \frac{Q}{2},
$$

is Crowther's formulation ${ }^{10}$ ! Monahan could then have used this function instead of (17), and it would have been only slightly more challenging (see also Section 7.1). This connection has, to our knowledge, never been identified. It is important, however, as if it had been recognised, it could have led to the unification of classic lot sizing models as early as 1984 .

Having missed this opportunity of realising that an analytically tractable approach to dealing with Monahan's AS function (18) exists, future work building upon Monahan (1984) has not taken up Monahan's final challenge, and consequently has not made the connection with Crowther's contribution. Most notably, Banerjee (1986) extended (17) to account for a finite production rate but lot-for-lot production (i.e. $m=1$ ), Goyal (1988) to the case of producing in lots of size $m Q$ at infinite production rate, and Joglekar (1988) to the case of producing in lots of size $m Q$ for an (in)finite production rate.

\footnotetext{
${ }^{9}$ We have simplified his equation by removing the extra parameters used for modelling the discount scheme.

${ }^{10}$ To be more precise, a function in between Crowther's original function, and Drezner and Wesolowsky's interpretation.
} 
We can retrieve the case as in Goyal (1988) from Theorem 1 by rearranging terms in (6) to find (10), as discussed previously, showing the shortcomings of Goyal's model. The insight that Monahan's main model, and all models building on it, should have included Crowther's term from the NPV-derived viewpoint, was first formulated in Boyaci and Gallego (2002). Beullens and Janssens (2011) show that this indeed holds for finite production rates in the model of Banerjee (1986), under conventional payments, and Beullens and Janssens (2013) presented similar findings for the general model of Joglekar (1988) under both conventional and other payment structures.

\section{Clark (1958)}

A few years before Crowther, Clark (1958) and Clark and Scarf (1960) laid the foundations for what is now known as multi-echelon inventory theory. Their contribution to inventory theory has arguably been even more influential than Harris'. The nature of their contribution was the derivation of optimal policies based on dynamic programming across a serial line of stocking points or installations, see also Figure 1, and where final demand occuring at the most downstream installation could be stochastic and dynamic, and where backlogging is permitted. Key to the success of their approach was the introduction of the concept of a multi-echelon system, which allowed them to separate the problem into solving a series of single-echelon problems. This was first proposed in Clark (1958), see also Scarf (2004). Clark defines an echelon as a system in which the stock is comprised of the stock at the corresponding installation plus all stock towards and at the next downstream echelon. In other words, and in the case that lead-times are zero and backlogging is not allowed, the echelon stock at installation $i$ in Figure 1 is the stock held at installation $i$, plus all the stock held at the downstream installations $i-1, \ldots 1$, and not yet sold to the final customers. In addition, Clark defines the concept of a unit echelon holding cost, explained below.

We now consider the textbook serial multi-echelon inventory system described in Hillier and Lieberman (2005) and Silver et al. (1998) and depicted in Figure 1. This is a severe simplification of the model of Clark and Scarf, but the assumptions of this simple model are in line with those of models discussed previously in this paper. There are $n$ echelons, $i \in N=\{1,2, \ldots, n\}$, where echelon $i=1$ serves final customer demand according to a deterministic constant rate of $y$ units of product per unit of time. Let $\mathcal{Q}=\left\{Q_{i} \mid\right.$ $\left.Q_{i} \in \Re^{+}, i \in N ; Q_{i}=m_{i} Q_{i-1}, i \in N \backslash\{1\}, m_{i} \in \mathbb{N} \backslash\{0\}\right\}$ be the collec- 
tion of stationary-nested lot-size policies, where echelon 1 receives products in a lot-size $Q_{1}$ from echelon 2 , echelon $i>1$ receives from echelon $i+1$ the lot-size $Q_{i}=m_{i} Q_{i-1}$, and echelon $n$ always orders the lot-size $Q_{n}$ from an outside supplier. Each echelon produces at an infinite production rate, and lead-times are zero. The problem calls for finding a policy from $\mathcal{Q}$ that minimises the supply chain (SC) average costs.

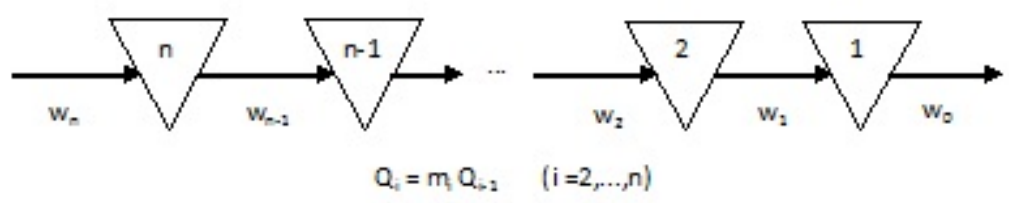

Figure 1: Serial multi-echelon inventory system

The textbook solution extends the approach introduced in Harris (1913) that the SC-optimal lot-sizes are found from the trade-off between average set-up costs and average holding costs. A distinction is made between installation holding costs and echelon holding costs. The former approach leads to the following $\mathrm{SC}$ average cost function $A C$ :

$$
A C=\sum_{i=1}^{n} A C_{i}=\sum_{i=1}^{n}\left[s_{i} \frac{y}{Q_{i}}+h_{i} E\left(I_{i}\right)\right],
$$

where $s_{i}$ is fixed cost per order or production set-up; $h_{i}$ the unit holding cost, which, following Clark (1958), should be based on the 'value added' at installation $i$ plus all the already 'added value' in the upstream installations $i+1$ to $n$; and $E\left(I_{i}\right)$ is the average physical or installation stock held at $i$ : $E\left(I_{i}\right) \equiv \frac{m_{i}-1}{2 m_{i}} Q_{i}$ for $i \in N \backslash\{1\}$, and $E\left(I_{1}\right) \equiv \frac{Q_{1}}{2}$.

The study of inventories in even this simple supply chain, however, is often based on Clark's concepts of echelon stocks and unit echelon holding costs. The unit echelon holding cost $\tilde{h}_{i}$ at echelon $i$ is defined as the holding cost on the 'added value' by converting the product from echelon $i+1$ to echelon $i$. It thus holds that $h_{i}=\sum_{j=i}^{n} \tilde{h}_{j}, \forall i \in N, \tilde{h}_{i}=h_{i}-h_{i+1}, \forall i \in N \backslash\{n\}$, and $\tilde{h}_{n} \equiv h_{n}$. It is well-known that the summation over the echelon holding costs $\widehat{A C}_{i}$ produces:

$$
A C=\sum_{i=1}^{n} \widetilde{A C_{i}}=\sum_{i=1}^{n}\left[s_{i} \frac{y}{Q_{i}}+\tilde{h}_{i} E\left(\tilde{I}_{i}\right)\right],
$$


where $E\left(\tilde{I}_{i}\right) \equiv \frac{Q_{i}}{2}$ is the average echelon stock of echelon $i \in N$.

Both formulations are equivalent from a total cost point of view. Indeed, echelon average cost equations $\widetilde{A C}_{i}=s_{i} \frac{y}{Q_{i}}+\tilde{h}_{i} E\left(\tilde{I}_{i}\right)$ can be retrieved from the installation average costs equations $A C_{i}=s_{i} \frac{y}{Q_{i}}+h_{i} E\left(I_{i}\right)$ by adding the terms $h_{i} \sum_{j=1}^{i-1} E\left(I_{j}\right)$ to $A C_{i}$ of each echelon $i \in N \backslash\{1\}$, and subtracting the same terms $h_{i+1} \sum_{j=1}^{i} E\left(I_{j}\right)$ from the $A C_{i}$ of each echelon $i \in N \backslash\{n\}$. This converts (20) into the equivalent (21). (Likewise, installation costs can be retrieved from echelon costs by a similar addition and subtracting process.) The adding and subtracting process of equal terms to different echelons has a net zero impact on the sum of their costs and justifies the use of echelon stocks and unit echelon holding costs for supply chain optimisation.

However, it is also clear from the echelon stock and echelon unit holding cost definitions, and from the above addition and subtraction process, that $A C_{i} \neq \widetilde{A C}_{i}$. If $A C_{i}$ would represent the true direct costs incurred by echelon $i$, then its echelon cost function does not (and vice versa). Clark and Scarf did not claim that either $A C_{i}$ or $\widetilde{A C}_{i}$ is the true cost of installation $i$. They were interested in the optimal policy to minimise the total costs in the supply chain, not in the direct costs (or profits) of an echelon.

Using Theorem 1, we can derive what the profit function of each installation $i$ would be. Indeed, the structure of the problem for each installation $i>1$ fits the requirements of that model, whereas for the most downstream installation $i=1$ it is an EOQ problem. Let us call an installation a firm from now on. Instead of using $c$ as the total cost invested per unit of product, we need to split this up into at least two parts: the amount that is paid out to the upstream firm for acquiring the materials, and the amount that the firm itself further invests into the products. To model the first payments, let $W=\left\{w_{i} \mid w_{i} \in \Re, i \in N \cup\{0\}\right\}$ be a set of unit transfer prices, where $w_{0}$ is the price the final customer pays to firm $1, w_{i}$ the transfer price paid by firm $i$ to firm $i+1$, for $1 \leq i<n$, and $w_{n}$ the price firm $n$ pays to the outside supplier. Let $e_{i}$ denote how much firm $i \in N$ invests per unit of product. This is necessarily paid out to some party external to the collective $N$.

As a corollary to Theorem 1, we hence obtain the following result.

Corollary 1. The profit function for each firm $i>1$ is given by:

$$
\begin{aligned}
\Pi_{i} & =\left(w_{i-1}-w_{i}-e_{i}\right) y-\left(\frac{s_{i}}{m_{i}}\right) \frac{y}{Q_{i-1}}-\alpha_{i} \frac{s_{i}}{2} \\
& -\alpha_{i}\left(w_{i}+e_{i}\right) E\left(\tilde{I}_{i}\right)+\alpha_{i} w_{i-1} E\left(\tilde{I}_{i-1}\right),
\end{aligned}
$$


in which the last two terms account for the opportunity costs and opportunity rewards for the firm, respectively, and which can be rewritten as:

$$
-\alpha_{i}\left(w_{i}+e_{i}\right) E\left(I_{i}\right)+\alpha_{i}\left(w_{i-1}-w_{i}-e_{i}\right) E\left(\tilde{I}_{i-1}\right) .
$$

Proof. For $c_{i}=w_{i}+e_{i}$, taking $s_{p}=0$, and by adding subscripts to the other parameters and variables where needed, (6) shows that each firm $i>1$ has the profit function $\Pi_{i}$ :

$$
\begin{aligned}
\Pi_{i}= & \left(w_{i-1}-w_{i}-e_{i}\right) y-\left(\frac{s_{i}}{m_{i}}\right) \frac{y}{Q_{i-1}}-\alpha_{i} \frac{s_{i}}{2} \\
& -\alpha_{i}\left(m_{i}\left(w_{i}+e_{i}\right)-w_{i-1}\right) \frac{Q_{i-1}}{2} .
\end{aligned}
$$

Substituting the definitions of average installation stocks and average echelon stocks introduced above, leads to the result. $\diamond$

Hence, the profit function of each of these suppliers should account for the opportunity cost using Harris' unit holding cost $\alpha_{i}\left(w_{i}+e_{i}\right)$ and the echelon stock of the firm, and account for the opportunity reward based on what we would call a unit revenue reward $\alpha_{i} w_{i-1}$ and the echelon stock of the downstream firm. This insight was first derived in Beullens and Janssens (2011). Note that we have derived their profit functions (for non-zero leadtimes) simply by application of Theorem 1 .

For firm 1, the profit function is based on the EOQ model:

$$
\Pi_{1}=\left(w_{0}-w_{1}-e_{1}\right) y-s_{1} \frac{y}{Q_{1}}-\alpha_{1} \frac{s_{1}}{2}-\alpha_{1}\left(w_{1}+e_{1}\right) \frac{Q_{1}}{2} .
$$

It is further rewarding to establish the relationship between the total joint profit function of these firms to the total cost functions (20) and (21). This is provided by the following two corollaries.

Corollary 2. The total profit function $\Pi_{N}$ for the collection of firms $\mathcal{N}$ is given by:

$$
\Pi_{N}=\left(w_{0}-w_{n}\right) y-\sum_{i=1}^{n}\left[e_{i} y+\frac{s_{i} y}{Q_{i}}+\alpha \frac{s_{i}}{2}+\alpha e_{i} \frac{Q_{i}}{2}\right]-\alpha w_{n} \frac{Q_{n}}{2},
$$

under the assumption that $\alpha_{i}=\alpha, \forall i \in \mathcal{N}$. 
Proof. Take the sum of the profit functions of the individual firms of $\mathcal{N}$ as given by (24) and (25). $\diamond$

Corollary 3. The terms as a function of lot sizes in $\Pi_{N}$ are equivalent to (20) and (21) if the unit echelon holding costs in the textbook serial multiechelon model are $\tilde{h}_{i}=\alpha_{i} e_{i}, \forall i \in \mathcal{N} \backslash\{n\}$ and $\tilde{h}_{n}=\alpha_{n}\left(w_{n}+e_{n}\right)$.

Proof. This follows easily from inspection. $\diamond$

It follows that the unit holding costs in the textbook multi-echelon model must exclude the transfer prices: $h_{i}=\alpha_{i}\left(w_{n}+\sum_{j=i}^{n} e_{j}\right), \forall i \in \mathcal{N}$, in order to correctly represent the SC profit function. Hence, while the profit functions of the individual firms need to account for the transfer prices in their holding cost terms, as in Harris' model, the 'holding cost' assigned to each installation in multi-echelon theory should exclude them. It therefore seems necessary to take a corrective action when using multi-echelon theory principles by explicitly stating that these transfer prices are not to be accounted for, as correctly applied in e.g. Chen et al. (2001). Many models in the literature do not invoke such corrections, and this may be because this was not considered in the early seminal work on joint economic lot sizing models, such as Banerjee (1986), Joglekar (1988) and Goyal (1988). This leads to a joint profit function which is still a function of the transfer prices, even if the opportunity cost of capital of all firms are equal. The reason why we do not run into these problems when deriving the models from NPV principles is that the supplier's reward as introduced by Crowther will automatically be included into the profit functions of the firms, and this ensures that the process of summation of their invidividual profit functions will lead to the correct joint profit function that is in line with the multi-echelon principles of Clark, and this without taking any corrective action. Crowther's contribution is hence important in making the connection between Harris's model and Clark's multi-echelon principles.

It also follows that, insofar the firm's opportunity costs are the same, that there is no difference regarding which profit functions to use between the case that these firms are really independent and the case that they would represent business units of a vertically integrated large firm. Confusion around this issue is evident in the literature, see e.g. Abad (1994). The differences between independent firms versus an integrated firm have to be rather sought in the fact that the opportunity cost of capital of individual firms may be 
very different, see Boyaci and Gallego (2002), or that the payment structures are no longer symmetric, see Beullens and Janssens (2013). This requires a closer investigation into the implications of corporate finance theory on models of logistics in supply chains, and multi-echelon lot sizing models in particular.

The individual profit functions (22) are valid for any value of the transfer prices under conventional payments. The following two corollaries establish the conditions under which one may claim that either $A C_{i}$ or $\widetilde{A C}_{i}$ would correctly represent the lot size-related costs to the individual firm in (22), $\forall i>1$, or $(25)$ for $i=1$. These conditions turn out not to be realistic for the case of independent firms, as all firms but the most downstream one must then operate at a net loss.

Corollary 4. For $\alpha_{i}>0$, the necessary conditions for $A C_{i}$ to represent the lot size dependent terms in (22), $\forall i>1$, or (25) for $i=1$, is that each echelon $i \in \mathcal{N} \backslash\{1\}$ must charge a unit price equal to its unit cost: $w_{i-1}=w_{i}+e_{i}$. Sufficient conditions for equality are then to take the unit holding cost $h_{i}=\alpha_{i}\left(w_{n}+\sum_{j=i}^{n} e_{j}\right), \forall i \in \mathcal{N}$.

Proof. The set-up cost terms are the same. We have to assume that both $h_{i}$ and the underlying payment structure is unknown. Comparing $A C_{i}$ in (20) to $(23)$, and since average echelon stocks $E\left(\tilde{I}_{i-1}\right)$ can take in general any nonnegative value not equal to $E\left(I_{i}\right)$, it must be that that: (a) $w_{i-1}=w_{i}+e_{i}$, $\forall i \in \mathcal{N} \backslash\{1\}$. Furthermore, it must be that: (b) $h_{i}=\alpha_{i}\left(w_{i}+e_{i}\right), \forall i \in \mathcal{N}$. Substitution of result (a) for $w_{i-1} \rightarrow w_{i}$ into (b), gives $h_{i}=\alpha_{i}\left(w_{i+1}+e_{i+1}+e_{i}\right)$. Continuing this substitution leads to the above result for $h_{i}$. These values for $h_{i}$ are sufficient for any payment structure to fit, but would be necessary to adopt for conventional payments. $\diamond$

Corollary 5. For $\alpha_{i}>0$, the necessary conditions for $\widetilde{A C}_{i}$ to represent the lot size dependent terms in (22), $\forall i>1$, or (25) for $i=1$, is that each echelon $i \in \mathcal{N} \backslash\{1\}$ must charge a zero unit price: $w_{i-1}=0$. Sufficient conditions for equality are then to take the unit echelon holding cost $\tilde{h}_{i}=\alpha_{i} e_{i}, \forall i \in \mathcal{N} \backslash$ $\{n\}$, and $\tilde{h}_{n}=\alpha_{n}\left(w_{n}+e_{n}\right)$.

Proof. The proof is the same, but now based on the comparison of $\widetilde{A C}_{i}$ in (21) to $(22)$.

It is clear that (5) is not only applicable in the serial supply-chain, but valid to any firm in any supply-chain configuration facing lumpy demand, as in e.g. Crowston et al. (1973). 


\section{Examples}

\subsection{Price discounts}

We compare the use of (6) as the profit function of the seller to the case in which Crowther's term is missing:

$$
\Pi=(w-c) y-\left(\frac{s}{m}+s_{p}\right) \frac{y}{Q}-\alpha \frac{s+s_{p}}{2}-\alpha c(m-1) \frac{Q}{2},
$$

as in Joglekar (1988), when resolving the price discount problem addressed in Joglekar (1988). The buyer's function is as in (16).

In a 'status quo' scenario, there is some initial price $w$. The buyer takes $Q=Q^{*}=\sqrt{2 s_{b} y /\left(\alpha_{b} w\right)}$ as to minimise (16). The supplier then determines $m^{*}\left(Q^{*}\right)$ by maximising (7) (NPV-approach, i.e. 'with Crowther') or, (27) (classic approach, i.e. 'without Crowther'). The supplier will now change the scenario and act as a Stackelberg leader by proposing a price discount scheme, prior to the vendor setting $Q$, with the aim to boost his own profits. In a price discount scheme $(\beta, \gamma)$, the vendor offers the buyer a reduced price $\beta w(\beta \leq 1)$ on all units in the order, if and only if the buyer would order in lot-sizes not smaller than some value $\gamma Q^{*}(\gamma \geq 1)$, where $Q^{*}$ can be interpreted as that value that the buyer choses for a price discount scheme $\gamma=\beta=1$

The buyer will not accept scheme $(\beta<1, \gamma>1)$ if this lowers his profits below what he could achieve in the status quo scenario, and will instead continue ordering at $Q^{*}$ for unit price $w$. If he would accept and hence receive the price $\beta w$, but is still free to choose the quantity, his optimal quantity would be $Q^{* *}=\sqrt{2 s_{b} y /\left(\alpha_{b} \beta w\right)}$. Accepting the scheme thus implies that the buyer orders $Q^{* * *}=\max \left\{\gamma Q^{*}, Q^{* *}\right\}$. Assuming, as in Joglekar (1988), that the buyer will still accept the scheme when his profits are equal to those obtained in the status quo scenario, allows the derivation of an upper bound on the optimal value of $\beta$ for any given $\gamma$, that the supplier may propose if this is still beneficial to himself. To assert this, he will thus determine $m^{*}\left(Q^{* * *}\right)$ using (7) or (27), and check whether his profits under the price discount scheme would increase relative to those he obtains in the status quo setting. A simple search routine over a range of $\gamma$ values in steps of 0.01 has been used to produce the results presented in Table 2 for the instances given in Table 1 (we take $s_{p}=0$ ). In column $7, \triangle \Pi$ is defined as the difference in vendor profits $\Pi$ between the price discount scheme and the 
Table 1: Problem instance characteristics

\begin{tabular}{|l|c|c|c|c|c|}
\hline$\#$ & $y$ & $s_{b}$ & $s$ & $w$ & $c$ \\
\hline 1 & 12,000 & 10 & 100 & 1.5 & 1.2 \\
2 & 12,000 & 10 & 100 & 3.6 & 1.2 \\
3 & 12,000 & 400 & 4 & 2.9 & 1.2 \\
\hline
\end{tabular}

status quo scenario, relative to vendor profits in the status quo scenario (and multiplied by 100).

While the approach to derive the optimal discount scheme is independent of the profit function that is used for the seller, the results found do depend crucially on the choice of function. Numerical results are given in Table 2 whenever a price discount scheme can be found that would increase the vendor's profits by more than $0.10 \%$. (In the other cases, the row contains ' $/$ ' entries.) Table 2 illustrates that if one does not account for the supplier's reward, the vendor sees less benefit in offering discounts, and the 'optimal' schemes are typically much less aggressive in lot-size quantities demanded and price discounts offered. Note that $\triangle \Pi$ in both frameworks may arbitrarily increase by more than the percentages reported if fixed overhead costs (which can be large in practice) would be accounted for.

Table 2: Optimal price-discount schemes for the vendor

\begin{tabular}{|l|c|c|c|c|c|c|c|}
\hline$\#$ & Model & $\gamma^{*}$ & $\beta^{*}$ & $Q^{* * *}$ & $m^{*}\left(Q^{* * *}\right)$ & $\triangle \Pi(\%)$ & $\triangle \Pi(\%)(E)$ \\
\hline 1 & With Crowther & 3.65 & 0.986 & 3,267 & 1 & 3.45 & 1.29 \\
1 & Without Crowther & 1.87 & 0.997 & 1,674 & 2 & 1.50 & 2.35 \\
2 & With Crowther & 5.88 & 0.981 & 3,399 & 1 & 0.61 & -1.72 \\
2 & Without Crowther & $/$ & $/$ & $/$ & $/$ & $<<0.1$ & $/$ \\
3 & With Crowther & 1.53 & 0.994 & 6,226 & 1 & 0.72 & -1.00 \\
3 & Without Crowther & $/$ & $/$ & $/$ & $/$ & $<<0.1$ & $/$ \\
\hline
\end{tabular}

$(E)$ When evaluating price discount scheme through the eyes of the other framework.

Table 2, last column, reports how the discount scheme is evaluated using the other framework's supplier function. If one believes that one should not consider Crowther's term, one would conclude that the NPV-derived discount scheme will reduce the vendor's profits in \#2 and \#3! If one accepts (6) as the true profit function, then one sees more merit in the solutions that are arrived at when ignoring the supplier's reward, however one does not recognise them as optimal. 


\subsection{Impact of production cost}

Imagine the following problem. The supplier receives an offer from a company that has a technology that can reduce the supplier's variable production costs $c$ by $x \%$. How large is the investment value $B$ that the supplier should be willing to pay this company now for acquiring this new technology and

use it to produce all future demand? The solution is clearly arrived at from solving the following equation:

$$
\alpha B=\triangle \Pi
$$

where $\triangle \Pi$ is the net difference between the profit obtained using the new technology and using the current technology. Assume for simplicity that the company always produces lot-for-lot at an infinite rate. Then using (27), (28) simplifies to $B=x y / \alpha$, but using (6) gives $B=x(y / \alpha+Q / 2)$. The difference in willingness to pay values is hence:

$$
\frac{\triangle B}{B}=\frac{x(y / \alpha+Q / 2)-x y / \alpha}{x y / \alpha}=\frac{\alpha Q}{2 y} .
$$

For $\alpha=0.2$ and $Q / y=0.2$, recognising the supplier's reward increases the maximum value that the firm is prepared to pay with $2 \%$, and for $Q / y=0.6$ with $6 \%$.

\subsection{Joint lot-size optimisation}

We use the seller-buyer situation of Section 7.1 (and $s_{p}=0$ ). The buyer, selling to final customers at the unit price $r$, has the profit function:

$$
\Pi_{b}=(r-c) y-s_{b} \frac{y}{Q}-\alpha_{b} w \frac{Q}{2},
$$

while the seller, if not recognising Crowther's term, has the profit function (27). The joint profit function $\Pi_{J}$ is then:

$$
\Pi_{J}=(r-c) y-\left(s_{b}+\frac{s}{m}\right) \frac{y}{Q}-h_{b} \frac{Q}{2}-h \frac{(m-1) Q}{2},
$$

where $h_{b}=\alpha_{b} w$ and $h=\alpha c$. This model is as in Joglekar (1988). The joint optimal lot-sizes are hence:

$$
Q^{*}=\sqrt{\frac{2\left(s_{b}+s / m^{*}\right) y}{h\left(m^{*}-s\right)+h_{b}}},
$$




$$
m^{*}=\left\lfloor\frac{1+\sqrt{1+4 \frac{s\left(h_{b}-h\right)}{s_{b} h}}}{2}\right\rfloor .
$$

Recognising the supplier's reward, however, we use (6) for the seller's profit function, and provided that $\alpha_{b}=\alpha$, their sum $\Pi_{J}$ is given by:

$$
\Pi_{J}=(r-c) y-\left(s_{b}+\frac{s}{m}\right) \frac{y}{Q}-h \frac{m Q}{2},
$$

where $h=\alpha c$. The joint optimal lot-sizes are given by $m^{*}=1$ and:

$$
Q^{*}=\sqrt{\frac{2\left(s_{b}+s\right) y}{h}} .
$$

Table 3 reports the joint optimal lot-sizes for the instances of Table 1 . As the marginal profit terms are constant and the same in both classic and NPV functions (with Crowther), we report the 'logistics' (lot-size dependent) Average Costs as $A C_{b}=(r-w) y-\Pi_{b}, A C=(w-c) y-\Pi$, and $A C_{J}=$ $(r-c) y-\Pi_{J}$.

Table 3: Solutions for joint lot-size optimisation in the buyer-vendor supply chain

\begin{tabular}{|l|c|c|c|c|c|c|c|}
\hline$\#$ & Method & $m^{*}$ & $Q^{*}$ & $A C_{b}$ & $A C$ & $A C_{J}$ & Side-payment $\left(^{*}\right)$ \\
\hline 1 & With Crowther & 1 & 3,317 & 534 & 262 & 796 & 317 \\
1 & Without Crowther & 2 & 1,633 & 318 & 563 & 882 & 72 \\
2 & With Crowther & 1 & 3,317 & 1,230 & -434 & 796 & 901 \\
2 & Without Crowther & 4 & 764 & 432 & 668 & 1,100 & 21 \\
3 & With Crowther & 1 & 6,356 & 2,598 & $-1,073$ & 1,525 & 316 \\
3 & Without Crowther & 1 & 4,089 & 2,360 & 12 & 2,371 & 0 \\
\hline
\end{tabular}

$\left(^{*}\right)$ Side-payment to buyer; see Section 7.4

When comparing to a 'status quo' situation in which the buyer first decides on $Q$ as to maximise his own profits, and then the vendor selects $m$ as to maximise his own profits, then the classic approach finds that the benefits of joint optimisation remain modest (in fact, a reduction of total logistics costs in the supply chain by $4.74 \%, 0.77 \%$, and $0.00 \%$ for $\# 1$, \#2, and $\# 3$, respectively). In the NPV-derived model, these benefits are much larger $(11.45 \%$, $17.91 \%$, and $9.18 \%$, respectively). The negative costs for the vendor in the NPV approach for \#2 and \#3 are due to the net opportunity cost being negative as a consequence of the supplier's reward. 


\subsection{Side-payments}

In order for two firms, say 1 and 2, to accept the solution that maximises their joint profit compared to a status quo scenario, annuity stream sidepayments can be organised as to make the final profit distribution vector an imputation, which is a sufficient condition for a two-player cooperative game. If the Shapley value is selected, firm $k \in\{1,2\}$ is to pay $0.5\left(\Pi_{J}^{* *}-\right.$ $\left.\Pi_{J}^{*}\right)-\left(\Pi_{k}^{* *}-\Pi_{k}^{*}\right)>0$ to the other firm, where $\Pi_{J}^{* *}$ and $\Pi_{k}^{* *}$ are the global profits and profits of firm $k$ in the joint optimal solution, respectively, and $\Pi_{J}^{*}$ and $\Pi_{k}^{*}$ are the global profits and profits of the firm $k$ obtained in the status quo scenario, respectively. (A negative side-payment means that $k$ receives this amount from the other firm.) Firm $k$ incurs the final profits $\Pi_{k}^{*}+0.5\left(\Pi_{J}^{* *}-\Pi_{J}^{*}\right) \geq \Pi_{k}^{*}$, and thus prefers the joint optimal solution, which is hence after these side-payments also a Nash equilibrium.

The last column of Table 3 shows the side-payments received by the buyer for the examples of Section 7.3 in which the status-quo scenario is that the buyer decides upon his optimal lot-size first. As can be observed, the classic functions, not recognising opportunity rewards, significantly underestimate the side-payments.

\subsection{Five-echelon supply chain}

Consider a five-echelon supply chain (SC) with the data as given in Table 4. In status quo, $Q_{1}$ is first determined by firm 1 using (25); then $m_{2} Q_{1}=Q_{2}$ by firm $2 ; m_{3} Q_{2}=Q_{3}$ by firm 3 , and so on, using each time (24). The joint optimal lot-sizes are simultaneously derived from the collective's profit function (26). Table 5 compares this approach (With Cr.) to the approach without incorporating the supplier's reward (Without Cr.). For each of the firms, the supplier's reward $S R$ is explicitly listed in a separate column, while the average costs $A C$ reported consist of the set-up costs, holding costs, and supplier's rewards. $A C^{*}$ is this cost in status quo, and $A C^{* *}$ the cost from the joint optimisation of the lot-sizes.

Table 4: Instance characteristics for a five-echelon supply chain

\begin{tabular}{|l|c|c|c|c|c|c|}
\hline Echelon & 0 & 1 & 2 & 3 & 4 & 5 \\
\hline$w$ & 10 & 8 & 6 & 4 & 2 & 1 \\
$s$ & $/$ & 20 & 30 & 40 & 50 & 60 \\
\hline 12,$000 ;$ for each firm: unit purchase price $w ;$
\end{tabular}


The difference between the results, see in Table 5, are significant. Crowther's term lowers the cost of the upstream suppliers in the status-quo scenario; it even makes upstream suppliers in the supply chain optimal solution earn negative logistics costs, i.e. a net profit, as their own inventory costs are more than compensated by the inventory held at the downstream firm. By including Crowther's term the optimal lot-sizes in the joint optima are very different, and are equal to those that would be found from multi-echelon theory if one corrects the installation holding costs (Corollary 3). It can be calculated that the $\mathrm{SC}$ net cost reduction from adopting the $\mathrm{SC}$ optimal solution with Crowther's term included is $58.4 \%$, whereas without it, one only arrives at $12.4 \%$. In the eyes of the latter model, the lot-sizes found using Crowther would lead to a net increase in total costs of $46.4 \%$. Using our functions to evaluate the classic solution without Crowther, the net cost reduction would be $32.8 \%$, i.e. much larger than $12.4 \%$ but much less than the optimal solution.

Table 5: Solutions for the five-echelon supply chain

\begin{tabular}{|l|c|c|c|c|c|c|c|c|c|c|}
\hline Method & Firm & $Q^{*}$ & $m^{*}$ & $A C^{*}$ & $S R^{*}\left({ }^{1}\right)$ & $Q^{* *}$ & $m^{* *}$ & $A C^{* *}$ & $S R^{* *}\left({ }^{1}\right)$ & Side-P. $\left(^{*}\right)$ \\
\hline With Cr. & 1 & 548 & $/$ & 876 & 0 & 4,899 & $/$ & 3,968 & 0 & 3366.7 \\
& 2 & 548 & 1 & 547 & 110 & 4,899 & 1 & -906 & 980 & -1178.8 \\
& 3 & 1,096 & 2 & 548 & 110 & 4,899 & 1 & -882 & 980 & -1154.5 \\
& 4 & 2,192 & 2 & 274 & 219 & 4,899 & 1 & -857 & 980 & -856.2 \\
& 5 & 2,192 & 1 & 109 & 219 & 4,899 & 1 & -343 & 490 & -177.3 \\
& 1 & 548 & $/$ & 876 & $/$ & 1,319 & $/$ & 1,237 & $/$ & 435.5 \\
& 2 & 548 & 1 & 657 & $/$ & 1,319 & 1 & 273 & $/$ & -309.3 \\
& 3 & 1,096 & 2 & 657 & $/$ & 1,319 & 1 & 364 & $/$ & -218.5 \\
& 4 & 2,192 & 2 & 493 & $/$ & 2,638 & 2 & 491 & $/$ & 76.1 \\
& 5 & 2,192 & 1 & 328 & $/$ & 2,638 & 1 & 273 & $/$ & 19.2 \\
\hline
\end{tabular}

(1) $S R=$ supplier's reward; * Side-payment received

The last column of Table 5 lists the side-payments to be received (paid out if negative) in the case that the firms each wish to receive a fifth of the total profit gains from joint lot-size optimisation. The classic method without Crowther is not fairly compensating the 'retailer' and the upstream firms keep more than their fair share of profits. Indeed, even in the classic approach they earn supplier's rewards, it is just that this financial benefit is not brought to light and hence not accounted for in the compensation scheme.

If one would calculate the SC optimal policy from the multi-echelon total profit function in which the correct transfer-price free unit holding costs 
are used, one will find the joint optimal lot-sizes but one cannot determine the financial implications for the individual firms. The latter requires the precise specification of the payment structures adopted between the firms in the status-quo scenario, as well as those payment structures adopted in the integrated scenario.

\subsection{Unconventional payment structures}

The profit function (10) was derived for the conventional payment structure (C). There are, however, payment structures that differ significantly from these standard assumptions. Under full consignment (FC), the supplier 'retains ownership' of the inventory at its buyer and this is implemented by letting the buyer pay the vendor the price $w$ only at the moment a product is actually sold. In the case of partial consignment (PC), the buyer pays $c$ to the vendor when products are delivered, and the remainder $(w-c)$ when the items are sold by the buyer. In the case of a trade credit, the buyer pays $c$ to the vendor when the products are delivered, say at time $t$, and pays the remainder $(w-c)$ after a grace period at time $t+z T(\operatorname{GP}(z))$, where $z$ is a suitably chosen constant.

Let us rewrite (10) by introducing unit parameters (we set $s_{p}=0$ for simplicity):

$$
\Pi=(w-c) y-\frac{s y}{m Q}-\alpha \frac{s}{2}-h \frac{(m-1) Q}{2}+h_{r} \frac{Q}{2},
$$

where $h$ is the unit holding cost, $h_{r}$ is the financial unit supplier's reward. Assume that this supplier sells to a buyer with the normal EOQ problem as in (30) but replacing $\alpha_{b} w$ by $h_{b}$. One can prove from the annuity stream profit functions, following similar procedures as reported in Boyaci and Gallego (2002) and Beullens and Janssens (2013), that in all these cases the buyer and seller can use these profit functions provided that we redefine $h_{b}, h$ and $h_{r}$ as given in Table 6.

Table 6: Parameter values in the buyer-vendor supply chain

\begin{tabular}{|l|c|c|c|c|}
\hline Parameter & $C$ & $F C$ & $P C$ & $G P(z)$ \\
\hline$h_{b}$ & $\alpha_{b} w$ & 0 & $\alpha_{b} c$ & $\alpha_{b} c-\alpha_{b}(w-c)(1-2 z)$ \\
$h$ & $\alpha c$ & $\alpha c$ & $\alpha c$ & $\alpha c$ \\
$h_{r}$ & $\alpha(w-c)$ & $-\alpha c$ & 0 & $\alpha(w-c)(1-2 z)$ \\
\hline
\end{tabular}

Note that under $\operatorname{GP}(z)$, the unit supplier's reward is positive when $z<$ $1 / 2$, zero for $z=1 / 2$, and negative when $z>1 / 2$. The buyer's unit holding 
cost also depends on the value of $z$, and can be negative for $w>>c$ and $z>1 / 2$. Unconventional payment structures can hence change the unit supplier's reward from positive values into zero or negative values. In the same manner, these payment structures can also change the normal unit holding costs into zero or negative values. The FC and $\operatorname{GP}(z=1)$ schemes are also reported in Boyaci and Gallego (2002).

\subsection{Underbuilding the theory for JELS}

The model in Goyal (1976) is arguably one of the first dealing with what is now known as the Joint Economic Lot Sizing Problem (JELS). The functions are (using the notation of Section 6):

$$
\begin{gathered}
C_{1}=\frac{s_{1} y}{Q}+h_{1} \frac{Q}{2} \\
C_{2}=\frac{s_{2} y}{m Q}+h_{2}(m-1) \frac{Q}{2} \\
C_{1+2}=C_{1}+C_{2}=\left(s_{1}+\frac{s_{2}}{m}\right) \frac{y}{Q}+\left(h_{1}+h_{2}(m-1)\right) \frac{Q}{2}
\end{gathered}
$$

for the costs of buyer, vendor, and the integrated supply chain, respectively. It corresponds to the model we have compared with in Section 7.3, but using constant unit holding costs $h_{1}$ and $h_{2}$. He compares a status-quo scenario, in which the buyer first determines $Q$ from (37), and giving this order, the supplier then determines $m$ from (38), with the integrated solution where $(Q, m)$ are simultaneously determined from (39). Based on this comparison, he also develops a side-payment scheme so that both firms will fair better from adopting the integrated solution.

Corollary 6. Under conventional payments, the model of Goyal cannot lead to the determination of the benefit of an integrated approach in relation to an uncoordinated approach. It follows that it cannot be determined how to share the benefits of adopting the integrated solution among the participating firms.

PROOF. If we assume conventional payments, then according to Harris, $h_{1}$ should include the unit price $w_{1}$ that the buyer pays the supplier, for any value of $w_{1}$. This will lead the buyer to find the correct lot-size in status-quo, and since the supplier's reward is then constant, the supplier will find the

correct value for $m$ in status-quo. But then, as illustrated in Sections 7.3 and 
7.5, the joint optimal solution $(m, Q)$ will in general not be found since (39) does not represent the true joint cost function. Hence, the side-payments will also be miscalculated (as in e.g. Section 7.4).

On the other hand, according to the principles of Clark's multi-echelon theory, we can postulate that (39) is based on installation holding costs, hence be as in (26), and then $h_{1}$ will not be based on $w_{1}$ but on the unit cost price $w_{2}$ of the supplier (Corollary 3 ); the joint optimal solution $(m, Q)$ will hence be correctly identified. However, (37) and (38) then merely represent installation cost functions, which are not equal to the firms' true cost functions under conventional payments, unless the supplier operates at a net loss (Corollary 4 ), i.e. $w_{1}=w_{2}+e_{2}$ in this case. But Goyal's model should stand for any value $w_{1}$. Hence the status-quo solution, as well as the side-payments, will be miscalculated. $\diamond$

What is missing in the literature is the specification of the assumptions under which Goyal's model holds. Table 6 helps to clarify this: under conventional payment or full consignment, the model should be corrected by including a positive or negative supplier's reward, respectively.

Goyal's model stands, however, when the payment structure is partial consignment $(\mathrm{PC})$, see Table 6. In that case, the supplier gives away his Crowther's supplier's reward to his buyer. Both the holding cost at the buyer and at the supplier are then independent of the transfer price, and insofar the cost price $c$ remains constant, they can indeed be taken as constants.

The other case in which Goyal's model applies is when using a grace period with $z=1 / 2(\operatorname{GP}(z=1 / 2))$, see Table 6. Payment of the mark-up $(w-c) Q$ has to occur halfway through the inventory cycle. The implications to buyer and vendor with respect to their NPV profit functions are then exactly the same as under partial consignment.

The practical implementation of both $\mathrm{PC}$ and $\mathrm{GP}(z=1 / 2)$ may be more complicated then when applying conventional payments (C). Only sellers who have sufficient liquidity can offer these schemes to their buyers, since the money they receive upon the delivery of the batch to their customers only covers their unit costs. At that point in time, sellers have made a net loss since they have to carry their logistics costs as well as their allocated overhead costs (which are typically not included in the models but may be a significant part of their overall cost structure).

$\operatorname{GP}(z=1 / 2)$ has the additional drawback that, in practise, one has to establish when the next order of the buyer will be placed in order to find out 
when the payment is due. If it turns out that the buyer actually pays later than halfway into the inventory cycle, his holding costs go down, which will encourage him to buy in larger and larger lot sizes. This would not be in the best interests of the supplier, who would then need to be in an even better cash position in order to give this larger credit to its buyers. For $z>1 / 2$ values, the buyer's unit holding cost could in fact become lower than that of the supplier, and even may become negative depending on the value of $z$ and the mark-up $(w-c)$. This will give the seller an incentive to specify a fixed credit delay for the buyer instead, but in that case we no longer have the GP scheme but are back to a conventional payment structure (with constant credit delay) and where a non-zero supplier's reward would have to be taken into account.

\section{Further key results}

Further insightful demonstrations about the usefulness of NPV-thinking on revealing the demand-size implications to lot sizing are found in the following articles. That holding costs may need to be valued at sale price and not cost price, in certain situations, was first proven in Grubbström (1980). Beullens and Janssens (2011) provide another NPV solution to this model and show how both solutions can be seen to include Crowther's supplier reward. Boyaci and Gallego (2002) show the relevance of (10) for deriving an optimal revenue-sharing contract for the model of Roundy (1985). It is valuable to apply this approach to the problem in Chen et al. (2001); we think this leads to a much simpler derivation of results. Non-zero lead-times also produce effects similar to Crowther's, see Grubbström and Thorstenson (1986) and Beullens and Janssens (2011). Beullens and Janssens (2013) show the implications of different uncoventional payment structures for the EOQ model, the EPQ model Taft (1918), and the model of Joglekar (1988). Similar reward effects as identified by Crowther are identified. An NPV interpretation for the unit backorder cost, $\alpha(w-c)$, is obtained in Grubbström (1998), hence very similar to Crowther's. As backorders delay revenues, it may hence reduce Crowther's positive effects, but exact analytical relationships are yet not available. Insight into Crowther's reward effect in stochastic models is not yet established. Using NPV, Haneveld and Teunter (1998) and Farvid and Rosling (2014) derive valid objective functions from which to derive inventory policies, but do not derive profit functions that indicate how a firm could make profits from changing demand patterns. Their models lack a 
lot-size effect in the demand, an effect probably needed to arrive at impacts as significant as in Theorem 1. The model in Porteus (1985) is in this respect a better first candidate to demonstrate the implications derivable with respect to Crowther's insight. See also Section 10.

\section{Crowther in the literature}

Crowther is briefly mentioned in the reviews on quantity discounts of Dolan (1987), Benton and Park (1996), Munson and Rosenblatt (1998), and Viswanathan and Wang (2003), but his model is not discussed in detail nor reproduced. Most of the papers that classify themselves as following Crowther, actually follow the approach of Dolan (1978), including Lal and Staelin (1984); Dada and Srikanth (1987); Kohli and Park (1989, 1994); Lam and Wong (1996); Wang and Wu (2000); Wang (2002, 2005). The original meaning of the supplier's reward has eroded as $+\alpha(w-c)$ is replaced by a single parameter ' $h$ '.

As a result of the substition by ' $h$ ', the meaning of Crowther's term seems often misunderstood. Gurnani (2001), claiming to follow Crowther, changes its sign from positive (a reward) to negative (a cost). Crowther's model is almost exclusively applied without the consideration of the firm's traditional holding costs. Wang (2005) aims to integrate Crowther's model into a function akin to (10), but uses the same ' $h$ ' in the classic holding cost term and in Crowther's term, and this would only be valid under conventional payments in the special case that $w=2 c$.

In reviews on supply chain coordination models with lot sizing components, Crowther is not always present. He is briefly mentioned in Goyal and Gupta (1989), but absent from Thomas and Griffin (1996) and Maloni and Benton (1997), whereas Monahan and models extending his main model are more prominently featured. In Sarmah et al. (2006), Crowther is mentioned, and Drezner and Wesolowsky (1989) and Boyaci and Gallego (2002) are briefly discussed, while models following Monahan are explicitly reproduced. It does not report the findings in Boyaci and Gallego (2002) with respect to these models. Li and Wang (2007) mentions Crowther (1964) briefly, but not Drezner and Wesolowsky (1989) nor Boyaci and Gallego (2002), and devotes much more space reviewing articles following on from Monahan.

In the JELS reviews of Ben-Daya et al. (2008) and Glock (2012), Crowther

is not mentioned. This is understandable in the sense that they did not address the problem that Crowther was addressing. However, we now know 
that his model is of relevance to these problems as well, in particular whenever the joint optimal solution is to be compared with a case of no coordination, or the benefits from joint optimisation have to be distributed. An undoubtedly fruitful line of further investigation would be to re-examine the lot sizing models reviewed in all the above articles.

Andriolo et al. (2014) offer a comprehensive review on EOQ and EPQ models, but excludes literature on JELS models. It is the first review in which the NPV approach is prominently present. It includes price-discounts and trade credits (permissible delays of payment) but from the buyer's perspective. The review of key findings presented in this paper derived from NPV is therefore complementary to Andriolo et al. (2014), and points towards an additional important research direction.

There are numerous recent articles which are not accounting for Crowther's reward effect, and hence it is uncertain whether these can be brought in line with NPV thinking. For example: in Shin and Benton (2007) a discount approach is investigated based on a model which in essence leads to the same discrepancies as reported in Section 7.1; in Esmaeili et al. (2009) seller-buyer Stackelberg games are developed based on a model that has the same deficiencies as reported in Section 7.3; in Bylka (2009) production and shipment lot sizes are determined in a buyer-seller model that has the shortcomings of the JELS model reported in Section 7.7; in Sana (2012) a 3-echelon supply chain is investigated that has the problems as reported in Section 7.5; and Ke and Bookbinder (2012) claim to use Crowther but consider it to be a cost rather than a reward. These are just a few examples of a large set of literature. This paper demonstrates that the four key papers of Harris, Crowther, Clark, and Monahan (when including his last refinements) are in line with NPV principles, and it seems logical to expect that all other lot sizing models derived from them should also have this characteristic. By acknowledging Crowther's contribution, while recognising that it may change its shape depending on payment structures, future research can avoid falling into these inconsistencies and give better assurance of helping firms to maximise the NPV of their lot sizing activities.

\section{The EOQ for regenerative procurement and sales processes}

We develop some new results, not with the intention to provide a full characterisation of the problem nor to derive any inventory policies, but with the aim to convey that Crowther's insight can be generalised to stochastic 
settings. We deviate from previous notation in that we assign a different interpretation to the indices $p$ and $s$, as explained further.

A firm purchases goods, adds value, and then sells them on to other firms. Let $c$ be the unit price it has to pay its supplier, and $e$ be the unit cost of additional value added by some production process working at infinite rate. The firm, in an aim to make profits, sells the goods at a unit price $w$ and at a constant rate of $y(w)$ units per year. Sales occurs in lot-sizes according to a regenerative process with i.i.d. cycle times $\left\{T_{s 1}, T_{s 2}, \ldots\right\}$. Let $Q_{s}$ and $T_{s}$ be two random variables representing the lot-size and cycle time, respectively. For any particular realisation of the $i^{\text {th }}$ cycle time $T_{s i}$, let $Q_{s i}=y(w) T_{s i}$ be the corresponding lot-size required, where $Q_{s 1}$ would be delivered at time $0, Q_{s 2}$ at a time $T_{s 1}, Q_{s 3}$ at time $T_{s 1}+T_{s 2}$, etc. Procurement and production occur according to another regerative process with i.i.d. cycle times $\left\{T_{p 1}, T_{p 2}, \ldots\right\}$ characterised by the random variables $Q_{p}$ and $T_{p}$ and such that for the $i^{\text {th }}$ cycle time $T_{p i}$, we have $Q_{p i}=y(w) T_{p i}$, where $Q_{p 1}$ would be obtained at time $0, Q_{p 2}$ at a time $T_{p 1}, Q_{p 3}$ at time $T_{p 1}+T_{p 2}$, etc. Let $E[x]$ denote the mean, $\sigma^{2}(x)$ the variance, and $c_{v}^{2}(x)=\sigma^{2}(x) /(E[x])^{2}$ the squared coefficient of variation of random variable $x$.

The set-up cost associated with $Q_{s i}$ is the constant $s_{s}$, and the revenue received is $w Q_{s i}$; the set-up cost for a batch $Q_{p i}$ is the constant $s_{p}$, and the cost incurred is $(c+e) Q_{p i}$. These payments occur when the batch is delivered or obtained, respectively. It is clear that the expected value of the annuity stream profit function of the firm is to be of the following form:

$$
\begin{gathered}
E[\mathrm{AS}]=-\alpha s_{p}\left(1+\sum_{i=1}^{\infty} E\left[e^{-\alpha Y_{p}}\right]\right)-\alpha s_{s}\left(1+\sum_{i=1}^{\infty} E\left[e^{-\alpha Y_{s}}\right]\right) \\
-\alpha(c+e) y(w)\left(E\left[T_{s 1}\right]+\sum_{i=1}^{\infty} E\left[T_{s(i+1)} e^{-\alpha Y_{s}}\right]\right) \\
+\alpha w y(w)\left(E\left[T_{p 1}\right]+\sum_{i=1}^{\infty} E\left[T_{p(i+1)} e^{-\alpha Y_{p}}\right]\right)-E_{s s}-E_{b b}
\end{gathered}
$$

where

$$
Y_{x}=\sum_{j=1}^{i} T_{x j},
$$

and $E_{s s}$ is the expected annual cost of safety stock, and $E_{b b}$ the expected annual cost of delayed revenue from backorders. Porteus (1985) (Lemma 1) 
shows how, from the knowledge of the (cumulative) distribution functions of $T_{p}, T_{s}, Q_{p}$ and $Q_{s}$, and the application of the Laplace-Stieltjes transform methodology, one can find an explicit characterisation of $E[\mathrm{AS}]$ (in fact applicable for any first $n$ cycles), save for $E_{s s}$ and $E_{b b}$. However, in the context of comparing with classic average cost inventory models, it is more useful to consider the linear approximation in $\alpha$ of this function (Grubbström, 1980). We write $E[\overline{\mathrm{AS}}]$, the expected annuity stream profit function, as $\bar{\Pi}$.

Theorem 2. The linear approximation in $\alpha$ of the expected annuity stream profit function of the firm facing regenarative procurement and sales processes, is of the following form:

$$
\begin{gathered}
\bar{\Pi}=(w-c) y(w)-\bar{E}_{s s}-\bar{E}_{b b} \\
-\frac{s_{p} y(w)}{E\left[Q_{p}\right]}-\frac{s_{s} y(w)}{E\left[Q_{s}\right]}-\alpha \frac{s_{p}}{2}\left(1+c_{v}^{2}\left(Q_{p}\right)\right)-\alpha \frac{s_{s}}{2}\left(1+c_{v}^{2}\left(Q_{s}\right)\right) \\
-\alpha(c+e) \frac{E\left[Q_{p}\right]}{2}\left(1+c_{v}^{2}\left(Q_{p}\right)\right)+\alpha w \frac{E\left[Q_{s}\right]}{2}\left(1+c_{v}^{2}\left(Q_{s}\right)\right) .
\end{gathered}
$$

Proof. By direct application of Theorem 1 in Porteus (1985), and rearranging terms. $\diamond$

We note that (42) generalises (5), or conversely, that we can derive Theorem 1 as a special (deterministic) case of Theorem 2 .

Current stochastic models do not include the revenue term in their objective function, which is valid if the stochastic demand process is assumed given and not subject to change, and for the same reason the supplier's revenue reward (the last term in $\alpha w$ ) is not needed. However, as shown by (42), firms should find it in their interest to try to influence the sales lot size's average and its variability, as to increase the last term. The way in which this should be done will depend on both procurement and sales processes. Both lot sizing problems are connected, of course, since in order to reach adequate service levels, a firm must make sure that cumulative amounts purchased (including safety stock) can, at any realisation of demand, reasonably meet cumulative sales (including outstanding backorders).

The function (42) shows, even under the classic assumption of uncontrollable demand, that the financial cost to the firm of 'keeping stock' is related to $E\left[Q_{p}\right]\left(1+c_{v}^{2}\left(Q_{p}\right)\right) / 2$, which is not the average inventory that the firm holds 
(as it clearly isn't). A similar finding was reported in Section 3. One can think of it as the average echelon stock of the firm, similar to the interpretation provided in Section 6. However, both Theorem 2 and Theorem 1 prove that this is an unsatifactory interpretation in the light that we have had no need to specify what actually happens downstream once the products are sold on to the next firm. For the same reason, $E\left[Q_{s}\right]\left(1+c_{v}^{2}\left(Q_{s}\right)\right) / 2$ does not automatically need to carry the interpretation as an average (echelon) stock held by the next firm.

Let us define a perfect just-in-time and agile supply process as a procurement/production process with zero set-up costs for procurement/production orders, and with an infinite production rate of unlimited output capacity available at all times; and a service-oriented firm as a firm that does not consider it in to be in its long-term interest to create backorders in the pursuit of short-term profit, out of fear of loosing customers.

Theorem 3. The service-oriented firm with a perfect just-in-time and agile supply process facing a regenerative sales process has an expected average profit function:

$$
\begin{gathered}
\bar{\Pi}=(w-c) y(w)-\frac{s_{s} y(w)}{E\left[Q_{s}\right]} \\
-\alpha \frac{s_{s}}{2}\left(1+c_{v}^{2}\left(Q_{s}\right)\right)+\alpha(w-c-e) \frac{E\left[Q_{s}\right]}{2}\left(1+c_{v}^{2}\left(Q_{s}\right)\right) .
\end{gathered}
$$

PROOF. Having this perfect process means that $s_{p}=0$ and that chasing demand is then clearly the ideal strategy for the firm. The firm will choose $Q_{p i}$ to be exactly equal to $Q_{s i}$, and has no need to keep lot size and safety stock and can always meet demand without backorders. Hence (42) simplifies to $(43)$. $\diamond$

The model obtained is a stochastic version of the interpretation of Drezner and Wesolowsky (1989) of the model of Crowther (1964) (see Section 4). Such a firm will find it of value to focus on revenue management. It shows that, even if $y$ is constant, the firm may find value in sales strategies that either stimulate buyers to purchase in larger batches on average (e.g. quantity discounts), or in larger batches on occasions only (e.g. sales promotions) (meaning that they then buy in smaller lot sizes at other times). The main insight of Crowther, that larger batch quantities offer the potential to increase the firm's profits, is still preserved, but will need a more careful treatment 
in terms of which strategies are best deployed. Indeed, the potential of these strategies, and the best mix of sales strategies, are clearly linked to how the distribution function of the process will be affected by these sales strategies.

\section{Conclusions}

This paper has reviewed the history of some important contributions but of which the wider implications to lot sizing have somehow not been picked up in the mainstream literature. Next to presenting a detailed account of how the original models proposed by Harris, Crowther, Monahan, and the multi-echelon concepts of Clark, are connected, and are in spirit all in line with NPV principles, we find that credit has to be attributed in particular to Drezner and Wesolowsky, for their more accurate reformulation of Crowther's insight, and to Boyaci and Gallego, for pointing out its relevance in supply chain coordination problems, as well as to other authors who have contributed to developing the NPV approach. We have further strengthened the case for unification, and adoption of Crowther's contribution, by presenting several examples that help quantify the discrepancies which are still present in current research. We have also demonstrated that Crowther's insight is transferable to stochastic models.

In relation to further research, and in the presentation in textbooks and review articles, we believe that the findings presented are very important. The model of Section 3 offers a simple pathway towards a unified lot sizing approach in textbooks, and provides links back to Harris' original EOQ problem and his comment about irregular demand patterns, as well as to Crowther, whose contribution we find of almost equal significance in the light of understanding the effect of lot sizing on a firm's profit function. We have left out in our discussion the impact of out-of-pocket holding costs, since neither Harris, Crowther nor Monahan considered these costs. Including them merely adds an additional 'classic' holding cost term to a firm's profit function, see e.g. Boyaci and Gallego (2002) and also Beullens and Janssens (2013).

It is also important to point out that these findings should be interpreted with care as they are subject to the particular additional assumptions that were needed to construct the NPV model with which a classic model is compared. There are in principle an infinite number of NPV reference models we could use to compare a classic model with and, for some of these NPV models not yet explored, equivalence of the classic model may hold. The 
quest for finding (repairable) equivalence is further explained and illustrated in Beullens and Janssens (2013), and they call the method NPV Equivalence Analysis (NPVEA). The message perhaps is that we have not always been careful enough to specify the context in which a particular classic (or NPV) model is applicable. What NPVEA can offer is a deeper understanding of which assumptions we need to make explicit, and when adaptations to classic models are desirable. We have included an example in Section 7.7. A more intensive use of NPV modelling in textbooks on lot sizing to derive the impact of payment structures on inventory theory, seems therefore also recommendable.

\section{References}

Abad, P., 1994. Supplier pricing and lot sizing when demand is price sensitive. European Journal of Operational Research 78, 334-354.

Andriolo, A., Battini, D., Persona, A., Sgarbossa, F., Grubbström, R., 2014. A century of evolution from Harris' basic lot size model: Survey and research agenda. International Journal of Production Economics, http://dx.doi.org/10.1016/j.ijpe.2014.01.013 (in press).

Banerjee, A., 1986. On 'A quantity discount pricing model to increase vendor profits'. Management Science 32 (11), 1513-1517.

Ben-Daya, M., Darwish, M., Ertogal, K., 2008. The joint economic lot sizing problem: Review and extensions. European Journal of Operational Research 185, 726-742.

Benton, W., Park, S., 1996. A classification of literature on determining the lot-size under quantity discounts. European Journal of Operational Research 92, 219-238.

Beullens, P., Janssens, G., 2010. Supplier's reward: the missing link in average profit inventory models for buyer vendor coordination. Working paper Department of Mathematics, University of Portsmouth, 31p.

Beullens, P., Janssens, G., 2011. Holding costs under push or pull conditions - the impact of the Anchor Point. European Journal of Operational Research 215, 115-125.

Beullens, P., Janssens, G., 2013. Adapting inventory models for handling various payment structures using net present value equivalence analysis. International Journal of Production Economics, http://dx.doi.org/10.1016/j.ijpe.2013.09.013 (in press).

Boyaci, T., Gallego, G., 2002. Coordinating pricing and inventory replenishment policies for one wholesaler and one or more geographically dispersed retailers. International Journal of Production Economics 77, 95-111. 
Bylka, S., 2009. Non-cooperative strategies for production and shipments lot-sizing in the vendor-buyer system. International Journal of Production Economics 118, 243-252.

Chen, F., Federgruen, A., Zheng, Y., 2001. Coordination mechanisms for a distribution system with one supplier and multiple retailers. Management Science 47 (5), 693-708.

Clark, A., 1958. A dynamic, single-item, multi-echelon inventory model. RM-2297, Santa Monica, California, The RAND Corporation December.

Clark, A., Scarf, H., 1960. Optimal policies for a multi-echelon inventory problem. Management Science 6 (4), 475-490.

Crowston, W., Wagner, M., Williams, J., 1973. Economic lot size determination in multistage assembly systems. Management Science 19 (5), 517-527.

Crowther, J., 1964. Rationale of quantity discounts. Harvard Business Review 42, 121-127.

Dada, M., Srikanth, K., 1987. Pricing policies for quantity discounts. Management Science 33 (10), 1247-1252.

Disney, S., Warburton, R., 2012. On the Lambert W function: Economic order quantity applications and pedagogical considerations. International Journal of Production Economics 140 (2), 756-764.

Dolan, R., 1978. A normative model of industrial buyer response to quantity discounts. In: Jain, S. (Ed.), Research Frontiers in Marketing: Dialogues and Directions. American Marketing Association, Chicago, pp. 121-125.

Dolan, R., 1987. Quantity discounts: Managerial issues and research opportunities. Marketing Science 6 (1), 1-27.

Drezner, Z., Wesolowsky, G., 1989. Multi-buyer discount pricing. European Journal of Operational Research 40, 38-42.

Esmaeili, M., Aryanezhad, M., Zeephongsekul, P., 2009. A game theory approach in sellerbuyer supply chain. European Journal of Operational Research 195, 442-448.

Farvid, M., Rosling, K., 2014. The discounted (R,Q) inventory model - the shrewd accountant's heuristic. International Journal of Production Economics 149, 17-27.

García-Laguna, J., San-José, L., Cárdenas-Barrón, L., Sicillia, J., 2010. The integrality of the lot size in the basic EOQ and EPQ models: Applications to other productioninventory models. Applied Mathematics and Computation 215 (5), 1660-1672.

Glock, C., 2012. The joint economic lot size problem: A review. International Journal of Production Economics 135, 671-686.

Goyal, S., 1976. An integrated inventory model for a single supplier - single customer problem. International Journal of Production Research 15 (1), 107-111. 
Goyal, S., 1988. A joint economic-lot-size model for purchaser and vendor: A comment. Decision Sciences 19, 236-241.

Goyal, S., Gupta, Y., 1989. Integrated inventory models: The buyer-vendor coordination. European Journal of Operational Research 41, 261-269.

Grubbström, R., 1967. On the application of the laplace transform to certain economic problems. Management Science 13 (7), 558-567.

Grubbström, R., 1980. A principle for determining the correct capital costs of work-inprogress and inventory. International Journal of Production Research 18 (2), 259-271.

Grubbström, R., 1998. A net present value approach to safety stocks in planned production. International Journal of Production Economics 56-57, 213-229.

Grubbström, R., 2014. Dynamic lotsizing with a finite production rate. International Journal of Production Economics 149, 68-79.

Grubbström, R., Molinder, A., 1994. Further theoretical considerations on the relationship between MPR, input-output analysis and multi echelon inventory systems. International Journal of Production Economics 35, 229-311.

Grubbström, R., Thorstenson, A., 1986. Evaluation of capital costs in a multi-level inventory system by means of the annuity stream principle. European Journal of Operational Research 24, 136-145.

Gurnani, H., 2001. A study of quantity discount pricing models with different ordering structures: Order coordination, order consolidation, and multi-tie ordering hierarchy. International Journal of Production Economics 72, 203-225.

Hadley, G., 1964. A comparison of order quantities computed using the average annual cost and the discounted cost. Management Science 10 (3), 472-476.

Haneveld, W., Teunter, R., 1998. Effects of discounting and demand rate variability on the EOQ. International Journal of Production Economics 54, 173-192.

Harris, F., 1913. How many parts to make at once. Factory, The Magazine of Management $10(2), 135-136,152$.

Hillier, F., Lieberman, G., 2005. Introduction to Operations Research, 8th ed. McGrawHill, New York.

Joglekar, P., 1988. Comments on 'A quantity discount pricing model to increase vendor profits'. Management Science 34 (11), 1391-1398.

Ke, G., Bookbinder, J., 2012. The optimal quantity discount that a supplier should offer. Journal of the Operational Research Society 63, 354-367. 
Kim, Y., Chung, K., Wood, W., 1984. A net present value framework for inventory analysis. Int. J. Physical Distribution and Logistics Management 14 (6), 68-76.

Kohli, R., Park, H., 1989. A cooperative game theory model of quantity discounts. Management Science 35 (6), 693-707.

Kohli, R., Park, H., 1994. Coordinating buyer-seller transactions across multiple products. Management Science 40 (9), 1145-1150.

Lal, R., Staelin, R., 1984. An approach for developing an optimal discount pricing policy. Management Science 30, 1524-1539.

Lam, S., Wong, D., 1996. A fuzzy mathematical model for the joint economic lot size problem with multiple price breaks. European Journal of Operational Research 95, $611-622$.

Li, X., Wang, Q., 2007. Coordination mechanisms of supply chain systems. European Journal of Operational Research 179, 1-16.

Maloni, M., Benton, W., 1997. Supply chain partnerships: Opportunities for operations research. European Journal of Operational Research 101, 419-429.

Monahan, J., 1984. A quantity discount pricing model to increase vendor profits. Management Science 30 (6), 720-726.

Munson, C., Rosenblatt, M., 1998. Theories and realities of quantity discounts: An exploratory study. Production and Operations Management 7 (4), 352-369.

Munson, C., Rosenblatt, M., 2001. Coordinating a three-level supply chain with quantity discounts. IIE Transactions 33, 371-384.

Peterson, R., Silver, E., 1985. Decision Systems for Inventory Management and Production Planning. Wiley, New York.

Porteus, E., 1985. Undiscounted approximations of discounted regenerative models. Operations Research Letters 3 (6), 293-300.

Roundy, R., 1985. 98\%-effective integer-ratio lot-sizing for one-warehouse multi-retailer systems. Management Science 31 (11), 1416-1430.

Sana, S., 2012. A collaborating inventory model in a supply chain. Economic Modelling 29, 2016-2023.

Sarmah, S., Acharya, D., Goyal, S., 2006. Buyer vendor coordination models in supply chain management. European Journal of Operational Research 175, 1-15.

Scarf, H., 2004. Comments on optimal policies for a multi-echelon inventory problem. Management Science 50 (12), 1791-1793. 
Shin, H., Benton, W., 2007. A quantity discount approach to supply chain coordination. European Journal of Operational Research 180, 601-616.

Silver, E., Pyke, D., Peterson, R., 1998. Inventory Management and Production Planning and Scheduling, 3th. ed. John-Wiley and Sons, New York.

Taft, E., 1918. The most economical production lot. Iron Age 101, 1410-1412.

Thomas, D., Griffin, P., 1996. Coordinated supply chain management. European Journal of Operational Research 94, 1-15.

Van der Laan, E., Teunter, R., 2002. Average costs versus net present value: a comparison for multi-source inventory models. In: Klose, A., Speranza, M., Van Wassenhove, L. (Eds.), Quantitative Approaches to Distribution Logistics and Supply Chain Management. Springer-Verlag, pp. 359-378.

Viswanathan, S., Wang, Q., 2003. Discount pricing decisions in distribution channels with price-senstive demand. European Journal of Operational Research 149, 571-587.

Wagner, H., Whitin, T., 1958. Dynamic version of the economic lot size model. Management Science 5 (1), 89-96.

Wang, Q., 2002. Determination of supplier's optimal quantity discount schedules with heterogeneous buyers. Naval Research Logistics 49, 46-59.

Wang, Q., 2005. Discount pricing policies and the coordination of decentralized distribution systems. Decision Sciences 36 (4), 627-646.

Wang, Q., Wu, Z., 2000. Improving a supplier's quantity discount gain from many different buyers. IIE Transactions 32, 1071-1079.

Williams, J., 1982. Note - on the optimality of integer lot size ratios in 'Economic lot size determination in multi-stage assembly systems'. Management Science 28 (11), 13411349 . 